\title{
Potencial para fontes alternativas de água em uma residência unifamiliar no município de Içara-SC
}

Ana Claudia Marcelino Bilesimo ${ }^{1}$,

Flávia Cauduro ${ }^{2}$.

Resumo: A água é um recurso fundamental contudo finito e a sua racionalização é uma preocupação global. Uma opção para redução do consumo de água potável é a implementação de alternativas de abastecimento em edificações. Sendo assim, estudou-se o potencial de economia de água de uma residência unifamiliar a partir da utilização de águas pluviais e cinzas. A habitação situa-se em Içara/SC, possui cinco moradores e área de cobertura servida de calhas igual a 283,37 $\mathrm{m}^{2}$. Realizou-se caracterização de consumo através de controle de frequência de uso e análise de contas de água da concessionária, resultando em uma média mensal de consumo igual a 13.371 L e valor diário per capita de 89,14 L. A distribuição percentual de uso mostrou que a geração de água cinza é menor que a demanda da mesma, porém, com a análise da precipitação, viu-se que a captação de água pluvial é capaz de suprir toda demanda por água de reuso. A economia máxima ficou em 38\% com utilização de água cinza e pluvial e 57\% com a utilização somente de água pluvial. Assim, optou-se pelo uso exclusivo de água pluvial. $\mathrm{O}$ reservatório foi dimensionado por três métodos: método de Rippl, método da Simulação e programa computacional Netuno. O primeiro método não gerou resultado pois o volume pluviométrico captado é maior que a demanda da edificação. No segundo e no terceiro métodos os valores de reservatório para aproveitamento máximo variaram sendo, respectivamete, 30.000 L e 6.000 L. Uma cisterna de 5.000L foi escolhida ponderando os métodos, a disponibilidade comercial e a área de terreno para instalação. A escolha gerou economia de água potável entre 5.348, L e 7.488 L mensais, o que representa entre $40 \%$ e $56 \%$ do consumo total da residência.

Palavras-chave: reuso de água; água pluvial; águas cinzas; reservatório; engenharia civil; água de chuva.

\section{Potential for alternative water sources in a single-family residence in Içara - SC}

\begin{abstract}
Water is a fundamental although finite resource and its rationalization is a global concern. Implementation of alternative water supply in buildings is an option to reduce portable water consumption. Therefore, the water saving potential of a single-family residence was studied by using rain and graywater. The house is located in Içara/SC, has five residents and $283.37 \mathrm{~m}^{2}$ of roof area served by gutters. Characterization of consumption was performed

1 Graduada, Departamento de Engenharia Civil, Universidade do Extremo Sul Catarinense, acbilesimo@unesc.net 2 Professor, Departamento de Engenharia Civil, Universidade do Extremo Sul Catarinense, flavia.cauduro@unesc.net
\end{abstract}




\section{Revista Técnico-Cientifica de Engenharia Civil CIVILTEC}

through use frequency table and analysis of water bills resulting in a monthly average of consumption equal to $13,371.43 \mathrm{~L}$ and daily value per capita of $89.14 \mathrm{~L}$. The use percentage distribution showed that the generation of graywater is less than the its demand, however, with the pecipitation analysis, it was seen that the rainwater catchment is able to supply the demand for reclaimed water. The percentage of maximum savings was $38 \%$ with gray and rainwater use and $57 \%$ with only rainwater use. Thereby, exclusive rainwater use was chosen. The tank size was calculated by three methods: Rippl method, Simulation method and computer program Netuno. The first method did not generate results because the rainfall volume collected is greater than the building demand. In the second and third methods the tank values for maximum utilization varied and it was, respectively, 30,000 L and 6,000L. A 5,000L cistern was chosen considering the methods, commercial availability and land area for installation. The choice generated a water saving between $5,348.57 \mathrm{~L}$ and $7,488.00 \mathrm{~L}$ monthly, which represents between $40 \%$ and $56 \%$ of residence's total consumption.

Key-words: reclaimed water; rainwater; greywater; tank; civil engineering.

\section{Introdução}

A água é um recurso único, indispensável e limitado. No ano de 2010, durante a Assembleia Geral de vinte e oito de julho, a Organização das Nações Unidas (ONU) reconheceu formalmente que o acesso à água potável e ao saneamento básico como um direito humano. A lei brasileira $\mathrm{n}^{\circ}$ 9.433, de 8 de janeiro de 1997, a qual instaura a Política Nacional de Recursos Hídricos, considera a água como "um bem de domínio público" e "um recurso natural limitado, dotado de valor econômico" e um de seus objetivos é "incentivar e promover a captação, a preservação e o aproveitamento de águas pluviais” (BRASIL, 1997). Em Santa Catarina, tevese uma atualização da lei n ${ }^{\circ}$ 9.022, de 1993, que trata do Sistema Estadual de Gerenciamento de Recursos Hídricos através da lei $\mathrm{n}^{\circ}$ 15.249, de 03 de agosto de 2010, reforçando a necessidade da correta gestão deste recurso, incluindo "estimular a educação ambiental, a pesquisa e a capacitação de recursos humanos para a gestão de recursos hídricos" (SANTA CATARINA, 2010). No dia 16 de julho de 2020, foi publicada a lei ${ }^{\circ} 14.026$ que atualiza o marco legal do saneamento básico. No seu decorrer, a lei busca a promoção de ações educacionais ambientais e em recursos hídricos e aborda o fomento a pesquisa e divulgação técnico-científica nas áreas de desenvolvimento sustentável, conservação e gestão de recursos hídricos e saneamento básico, incluindo o "desenvolvimento e o aperfeiçoamento de 


\section{Revisto Téenico-Cientifica \\ de Engenharia Civil CIVILTEC}

equipamentos e métodos economizadores de água”. A lei também prega o estímulo a racionalização pelos usuários e o fomento ao reuso de efluentes sanitários e ao aproveitamento de águas de chuva. Além disto, diz que fontes alternativas, complementares ou acessórias permitem a "possibilidade de as receitas serem compartilhadas entre o contratante e o contratado" e reforça a necessidade de promover a capacitação técnica do setor (BRASIL, 2020).

A movimentação buscando reconhecer a importância da água bem como sua finitude e necessidade de preservação é nítida. Shaffer e Leggett (2002) reforçam que a demanda de água aumentará no futuro juntamente com sua escassez, esta última derivada de agentes como o aquecimento global. Ngigi (1999) cita como causas para a carência de água a alarmante taxa de crescimento populacional, a degradação ambiental, competição pelo uso de recursos naturais, aumento da demanda devido a melhoria nos padrões de vida, a industrialização e irrigação. Regiões áridas e semi-áridas costumavam ser vistas como as únicas que sofriam com a falta de abastecimento porém isto não é mais verdade. Mesmo locais com vasta disponibilidade de água estão sofrendo, pois seus recursos não são suficientes para a demanda excessiva (ANA; FIESP; SINDUSCON-SP, 2005). Cerqueira et al. (2015) mostram que o uso não eficiente desse recurso é a principal causa do problema. A preocupação com a situação, segundo ANA; FIESP; SINDUSCON-SP (2005), está relacionada, entre outros, ao fato de o desenvolvimento agrícola, industrial e urbano dependerem de água, sendo sua escassez um fator limitante.

Aborda-se o gerenciamento da água em três frentes: Macro para escala das bacias hidrográficas, Meso para escala dos sistemas de saneamento e Micro para escala das edificações (GONÇALVES, 2009). Dessa forma, sistemas de reúso de água aplicados as edificações podem ser uma solução para restabelecer o equilíbrio perdido. ANA; FIESP; SINDUSCON-SP (2005) listam as formas de conservação de água como qualquer ação que:

\footnotetext{
$\checkmark$ reduza a quantidade de água extraída em fontes de suprimento;

$\checkmark$ reduza o consumo de água;

$\checkmark$ reduza o desperdício de água;

$\checkmark$ aumente a eficiência do uso de água; ou, ainda,

$\checkmark$ aumente a reciclagem e o reúso de água.
} 


\section{Revista Técnico-Cientifica \\ de Engenharia Civil CIVILTEC}

Duas possibilidades de redução do consumo de água potável proveniente das concessionárias são o uso de água pluvial e de águas cinzas (SHAFFER; LEGGETT, 2002). O uso da água pluvial baseia-se em coletar a água da chuva, a qual escorreria de volta ao ambiente, através das superfícies disponíveis na edificação, como os telhados (SHAFFER; LEGGETT, 2002; SANTANA; AMORIM, 2007) e, de acordo com ANA; FIESP; SINDUSCON-SP (2005), Jefferson et al. (1999), Shaffer e Leggett (2002) e Santana e Amorim (2007) as águas cinzas são as águas de efluente doméstico desconsiderando a participação de vasos sanitários, pias de cozinha e máquina de lavar louça.

Países como a Alemanha, Estados Unidos e o Japão já incentivam a conservação da água potável através desses dois sistemas de coleta e aproveitamento de água (MAY, 2009). A mesma autora informa que no Japão, EUA, Canadá, Alemanha, Reino Unido e Israel as águas cinzas são usadas como fontes alternativas para usos não potáveis. Cerqueira et al. (2015) sugerem a elevação da oferta de água através de, entre outros, "redução de perdas nos sistemas de abastecimento de água, aproveitamento de água de chuva, utilização de água de reúso" e ainda afirma que estas são alternativas aplicáveis a curto prazo.

Shaffer e Leggett (2002, p.189, tradução nossa) afirmam que "o uso de água pluvial e águas cinzas reduz a necessidade de água da rede, e em algumas circunstâncias, pode substituíla. Isso visa reduzir o custo direto, e diminuir a dependência da água da rede." Contudo, os mesmos autores ressaltam que diversas questões devem ser verificadas antes de iniciar a instalação dos sistemas.

Assim, embora de forma geral o reuso de águas em edificações seja uma das soluções para as questões hídricas pelo qual o mundo enfrenta, é necessário verificar e estudar os aspectos próprios e particulares de cada edificação para, então, poder-se afirmar que estas alternativas são viáveis para a mesma.

Tendo em vista o citado problema de escassez de água e o possível potencial de economia da mesma através da implementação dos usos alternativos para abastecimento de uma edificação, este trabalho tem como objetivo estudar a demanda de água de uma edificação residencial unifamiliar, seu potencial de coleta de água pluvial e água cinza para reuso em fins não potáveis e calcular a latente redução da quantidade de água potável consumida. 


\section{Revisto Téenico-Cientifica de Engenharia Civil CIVILTEC}

\section{Materiais e métodos}

A edificação residencial selecionada para a realização do estudo está localizada no bairro Centro na cidade de Içara em Santa Catarina, Brasil. O projeto arquitetônico é de 1998 e, segundo dados fornecidos pelos proprietários, a residência foi construída em 2000. Manutenções referentes a pintura externa e limpeza de caixa d'água foram realizadas ao longo dos 20 anos. Moram na residência cinco pessoas da mesma família.

Com área construída igual a 222,43 $\mathrm{m}^{2}$, a estrutura principal comporta em áreas secas: quatro quartos, duas salas de estar, sala de jantar, garagem, despensa, sótão, dois porões e duas varandas; em áreas molhadas: três banheiros, lavabo, cozinha, churrasqueira e área de serviço, além de duas torneiras de jardim. As áreas molhadas estão destacadas na Figura 1.

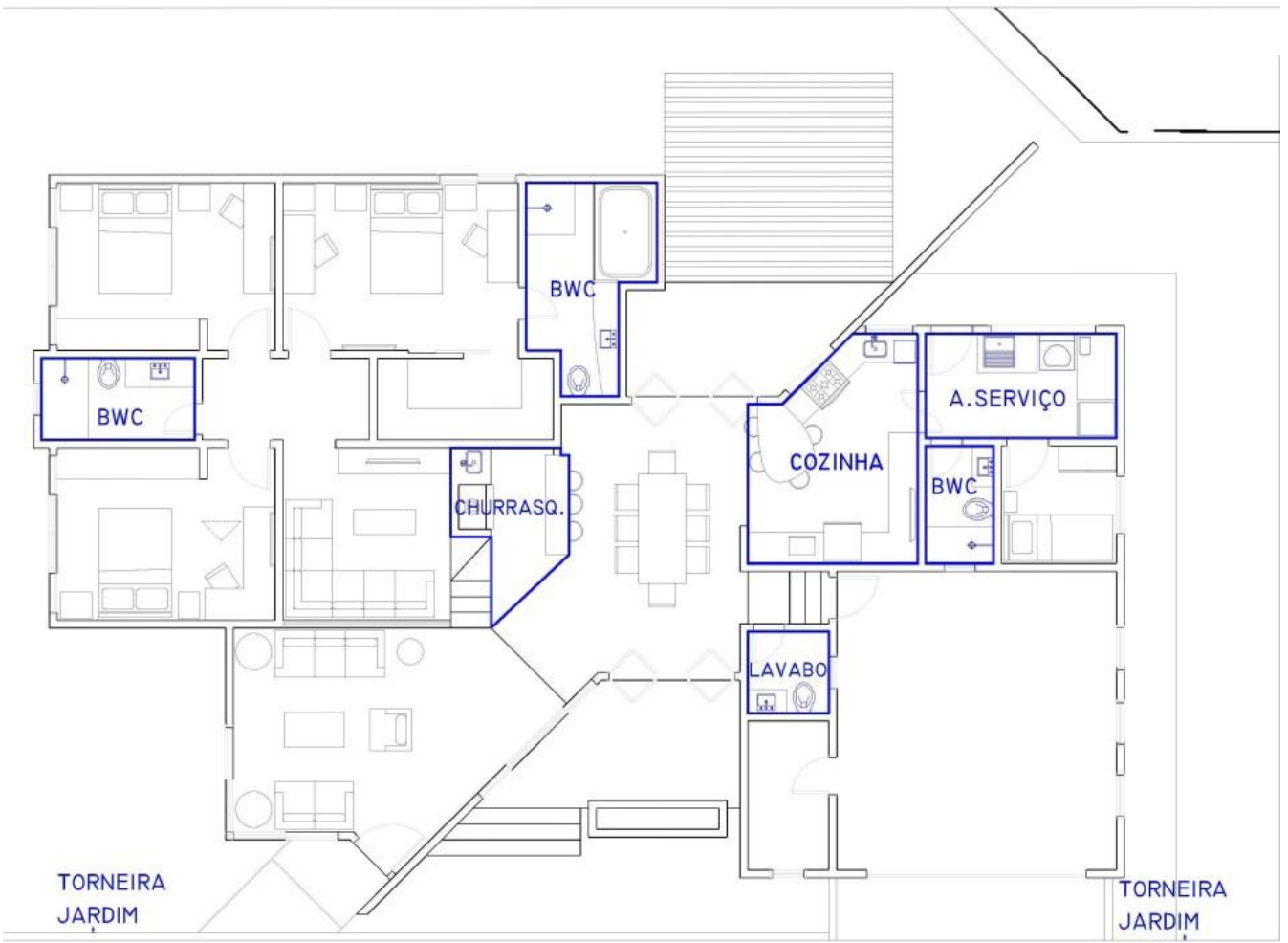

Figura 1. Áreas molhadas 


\section{Revisto Téenico-Cientifica de Engenharia Civil CIVILTEC}

A cobertura primária da habitação é em telha de concreto e tem inclinação de $20^{\circ} 41^{\prime}$. A mesma é composta por seis águas, mostradas na Figura 2, que juntas somam 283,37 $\mathrm{m}^{2}$ de área. A captação da água de chuva é feita através de calhas de zinco presentes em todo perímetro da cobertura.

O terreno em que a moradia se encontra possui $504 \mathrm{~m}^{2}$. Retirando-se a área ocupada pela casa, fossa séptca, sumidouro, calçada particular, espaço de varal, deque e marcenaria, restam aproximadamente $122 \mathrm{~m}^{2}$ em área de jardim onde é possível instalar reservatórios de água.

As características citadas indicam que a edificação possui tanto potencial de coleta de águas de reuso - cinza e pluvial - como possibilidade de emprego das mesmas.

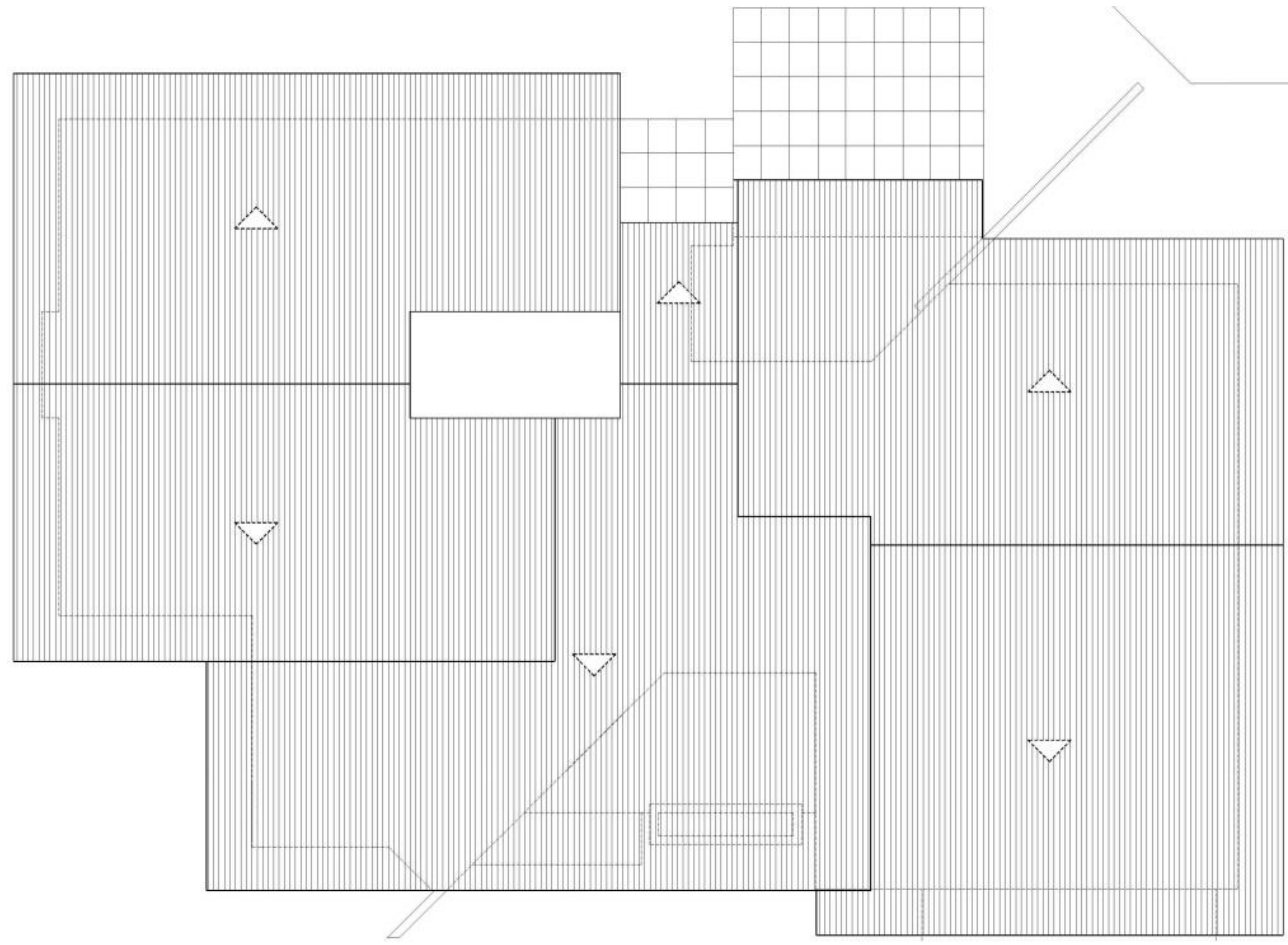

Figura 2. Área da cobertura

Para o desenvolvimento do estudo de reuso de água pluvial e cinza, é necessário fazer duas análises principais: análise de demanda e análise de oferta. Inseridas nessas duas grandes análises, estão as seguintes etapas de estudo (NGIGI, 1999; ANA; FIESP; SINDUSCON-SP, 2005; BRAGA, 2009; DANTAS, 2017; SANTOS, 2018): 


\section{Revisto Téenico-Cientifica \\ de Engenharia Civil CIVILTEC}

$\checkmark$ Caracterização de consumo e oferta de águas na edificação;

$\checkmark$ Avaliação do regime de chuvas e área de coleta;

$\checkmark$ Dimensionamento dos reservatórios.

Ao final dos estágios acima listados, calcula-se o volume mensal de água potável que pode ser economizado através da substituição por águas de reuso.

Iniciou-se esta etapa de caracterização do consumo com a obtenção do histórico de consumo mensal de água através do site da Companhia Catarinense de Águas e Saneamento (CASAN) por um período mínimo de um ano. Este período é essencial pois existem variações de consumo entre os meses do ano devido a fatores como condições climáticas, ocupação da edificação, renda e preço da água (NGIGI, 1999; SANTOS, 2018).

Seguiu-se, então, para a vistoria na edificação com o intuito de apurar número de moradores, os pontos de usos da água, informações técnicas dos equipamentos, como também, questionar os responsáveis sobre cronogramas irrigação de jardim, de limpezas de pisos e como estas são feitas. Com os primeiros dados pôde-se reconhecer os pontos de coleta para reuso de águas cinza e, juntamente com os dados seguintes, identificar locais passíveis de utilização de água pluvial ou cinza.

Para obter-se a frequência de uso dos equipamentos da residência e, assim, definir os volumes de água utilizados em cada equipamento, foram desenvolvidas tabelas de controle para cada cômodo de área molhada. As tabelas foram preenchidas pelos usuários conforme o uso durante o período de um mês.

Os volumes de água utilizados por uso para cada equipamento, quando possível, foram obtidos nos respectivos manuais. Para os equipamentos que não possuiam a informação disponível, o volume de água foi obtido multiplicando-se o tempo de uso pela vazão, sendo esta última medida através do método de Medição Direta de vazão com utilização de um cronômetro e um recipiente com volume conhecido.

Finalizando a caracterização de uso, dividiu-se os equipamentos em:

$\checkmark$ Utilização exclusiva de água potável;

$\checkmark$ Passíveis de utilizar água pluvial;

$\checkmark$ Geradores de água cinza; 


\section{Revisto Téenico-Cientifica \\ de Engenharia Civil CIVILTEC}

$\checkmark$ Passíveis de utilizar água cinza.

Com os valores calculados na caracterização de consumo, comparou-se, então, a demanda de água potável mensal da edificação com o volume passível de substituição por águas de reuso - pluvial e cinza. Assim, com um cálculo padrão de percentual, obteve-se o potencial máximo de redução de consumo de água potável que pode ser atingido. Fez-se o mesmo cálculo para águas pluviais exclusivamente, desconsiderando águas cinza.

Utilizando os dados históricos de precipitação fornecidos pela Agência Nacional de Águas (ANA) referentes a estação meteorológica de Içara-SC, relativos aos anos 1978 à 2019, calculou-se as médias mensais de precipitação. Contudo, a NBR 15527:2019, a qual trata do aproveitamento de água de chuva de coberturas para fins não potáveis, informa que, devido ao coeficiente de escoamento superficial da cobertura e a eficiência do sistema de descarte, o volume de chuva aproveitável não é o mesmo que o precipitado, sendo seu valor calculado segundo a Eq. 1.

$$
Q_{t}=P \times A \times C \times \eta_{\text {fator de captação }}
$$

em que:

Qt = volume anual, mensal ou diário de chuva aproveitável, em m³;

$\mathrm{P}$ = precipitação média anual, mensal ou diária, em mm;

$\mathrm{A}=$ área de coleta, expressa em metros quadrados, em $\mathrm{m}^{2} ;$

$\mathrm{C}=$ coeficiente de escoamento superficial da cobertura (runoff);

$\eta_{\text {fator de captação }}=$ eficiência do sistema de captação, levando em conta o dispositivo de descarte de sólidos e desvio de escoamento inicial, caso este último seja utilizado. Estes dados podem ser fornecidos pelo fabricante ou estimados pelo projetista. Na falta de dados, recomenda-se o fator de captação de 0,85 .

A área de coleta foi obtida através das plantas de cobertura da residência, levando em consideração somente a porção contemplada por calhas.

O valor do coeficiente de escoamento superficial da cobertura, também chamado de coeficiente de runoff, depende do material da cobertura. Segundo Fendrich (2002) as Telhas cerâmicas têm coeficiente de runoff igual a 0,8. 


\section{Revista Técnico-Cientifica \\ de Engenharia Civil CIVILTEC}

Sabendo dos dados de chuva aproveitável, verificou-se a possibilidade de o volume de água pluvial ser o suficiente para suprir as necessidades tanto dos equipamentos passíveis de uso pluvial quanto dos equipamentos passíveis de uso de água cinza. Esta averiguação foi feita pois foi entendido que, caso a água da chuva singularmente apresente a capacidade de abastecer a residência, não é interessante, de forma econômica e ambiental, instalar-se o sistema de reuso de águas cinzas.

A NBR 15527 foi atualizada no ano de 2019 e não traz métodos de dimensionamento para reservatório de água da chuva, deixando tal etapa a critério do projetista. Porém, a mesma afirma que devem ser levados em consideração: área de captação, regime pluviométrico e demanda de água não potável a ser atendida. Assim, optou-se por utilizar-se dois dos métodos apresentados na versão de 2007 da mesma norma, pois eles atendem aos requisitos e já foram amplamente estudados e aplicados.

Os métodos escolhidos a partir da NBR 15527:2007 foram: o Método de Rippl, o qual também foi utilizado por Dantas (2017) e Santos (2018), pois, de acordo com Ngigi (1999), este método é mais apropriado por não ser específico para uma região e ter uma aplicação ampla. Gonçalvez (2006, p.115) explica que o diagrama de massas calcula "volume de armazenamento necessário para garantir uma vazão regularizada constante durante o período mais crítico de estiagem observado"; e o método da Simulação, também utilizado por Rupp, Munarim e Ghisi (2011), Fontanela e Back (2010), Schroeder (2016) e Mandelli e Cauduro (2018), o qual baseia-se, de acordo com Rupp, Munarim e Ghisi (2011), "na determinação do percentual de consumo que será atendido em função de um tamanho de reservatório previamente definido".

Para o cálculo segundo o método de Rippl, precisa-se obter: o volume de água no reservatório no tempo, calculado pela Eq. 2, o volume de chuva aproveitável no tempo que foi obtido pela Eq. 1, e, enfim, o volume do reservatório através da Eq. 3.

$$
S_{t}=D_{t}-Q_{t}
$$

em que:

$\sum D_{t}<\sum Q_{t}$ 


\section{Revisto Técrico-Cientifica \\ de Engenharia Civil CIVILTEC}

$S_{t}=$ volume de água no reservatório no tempo t, em $\mathrm{m}^{3}$;

$D_{t}=$ demanda ou consumo no tempo $\mathrm{t}, \mathrm{em} \mathrm{m}^{3}$;

$Q_{t}=$ volume da chuva aproveitável no tempo t, em $\mathrm{m}^{3}$.

$$
V_{\text {Rippl }}=\sum S_{t}
$$

em que:

$V_{\text {Rippl }}=$ volume do reservatório por Rippl, em $\mathrm{m}^{3}$;

No método da Simulação, adota-se a equação da continuidade a um reservatório finito (NBR1552, 2007, p.6), calculada pela Eq. 4 e utiliza-se novamente a Eq. 1 para obter o volume de chuva aproveitável no tempo.

$$
S_{t}=Q_{t}+S_{t-1}-D_{t}
$$

sendo que:

$0 \leq S_{t} \leq V$

$S_{t}=$ volume de água no reservatório no tempo t, em $\mathrm{m}^{3}$;

$S_{t-1}=$ volume de água no reservatório no tempo t-1, em $\mathrm{m}^{3}$;

$D_{t}=$ demanda ou consumo no tempo $\mathrm{t}, \mathrm{em} \mathrm{m}^{3}$;

$Q_{t}=$ volume da chuva aproveitável no tempo t, em $\mathrm{m}^{3}$;

$V_{f}=$ volume do reservatório fixado, $\mathrm{em}^{3}$.

Além dos métodos sugeridos pela NBR 15527:2007, temos disponível o programa computacional Netuno desenvolvido no Laboratório de Eficiência Energética em Edificações (LABEEE) por Ghisi e Cordova (2014). Segundo Rupp, Munarim e Ghisi (2011, p.54), o Netuno "permite que se façam simulações do potencial de economia de água potável tanto para um volume de reservatório quanto para diversos volumes, ao mesmo tempo", desta forma, com os gráficos gerados, pode-se confrontar os volumes de reservatórios com seus potenciais de economia de água e fazer uma escolha mais clara. Para fins comparativos e visando uma escolha bem fundamentada, foi também realizado dimensionamento através do programa Netuno 4. Os dados de entrada requisitados foram: 


\section{Revisto Técrico-Cientifica de Engenharia Civil CIVILTEC}

$\checkmark$ Precipitação pluviométrica;

$\checkmark$ Área de captação;

$\checkmark$ Demanda diária de água potável per capita;

$\checkmark$ Número de moradores;

$\checkmark$ Porcentagem de água potável que pode ser substituída por pluvial;

$\checkmark$ Coeficiente de escoamento superficial.

O sistema de águas cinzas trabalha com ciclo diário, assim, possui menor reservatório cujo volume deve ser capaz de comportar a oferta de água cinza, calculada pela Eq. 5 (SANTOS, 2018), forma também aplicada por Maccarini e Cauduro (2017).

$$
Q_{a c}=I \times t
$$

em que:

$Q_{a c}=$ oferta de água cinza, $\mathrm{em} \mathrm{m}^{3} ;$

$I=$ indicador de consumo, $\mathrm{em} \mathrm{m}^{3} \mathrm{dia}^{-1}$;

$t=$ tempo, em dias.

O indicador de consumo e a oferta de água foram calculados na etapa de caracterização de consumo, será utilizado o formato litros por dia e o tempo adotado é igual a 1 (diário).

Com os valores obtidos nas etapas anteriores, reduziu-se do valor de consumo de água potável mensal da edificação a soma dos volumes suscetíveis a substituição por águas cinzas e pluviais. Comparou-se o resultado com o consumo atual e alcançou-se o valor latente de economia de consumo de água potável nesta residência.

\section{Resultados e discussões}

Através do site da CASAN, obteve-se o histórico de consumo mensal da residência. Optou-se por utilizar o máximo de tempo disponível, assim, o cálculo foi feito com os dados referentes aos últimos sete anos. A média mensal encontrada de consumo de água potável na residência foi de $13.371 \mathrm{~L}$. 


\section{Revista Técnico-Cientifica de Engenharia Civil CIVILTEC}

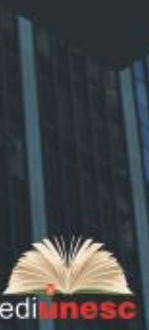

Há um total de cinco moradores no domicílio, assim, o consumo diário per capita é igual a 89 litros. Este valor está abaixo dos 112,60 $\mathrm{L} \mathrm{hab}^{-1} \mathrm{~d}^{-1}$ informado pelo Sistema Nacional de Informação sobre Saneamento (SNIS) para a cidade de Içara/SC (BRASIL, 2018). Tal fato pode ser explicado devido ao uso de equipamentos com tecnologia de redução de consumo de água e aos moradores possuírem hábitos econômicos.

Com as informações coletadas através das tabelas de frequência de uso dos equipamentos da residência e a média mensal de consumo calculada, obteve-se os percentuais de uso para cada equipamento e o volume de água correspondente, mostrados na Tabela 1. A divisão dos equipamentos, segundo o tipo de água que é passível de se utilizar e se há produção de água cinza, também está representada nesta tabela.

Tabela 1. Caracterização de consumo

\begin{tabular}{ccccc}
\hline Equipamento & Uso $(\%)$ & $\begin{array}{c}\text { Volume } \\
(\mathrm{L})\end{array}$ & $\begin{array}{c}\text { Tipo de água que } \\
\text { pode ser utilizada }\end{array}$ & $\begin{array}{c}\text { Produz água } \\
\text { cinza? }\end{array}$ \\
\hline Vaso sanitário & 38,20 & $5.107,72$ & Pluvial ou cinza & Não \\
Chuveiro & 29,68 & $3.969,31$ & Potável & Sim \\
Máquina de lavar roupa & 16,94 & $2.265,06$ & Pluvial & Sim \\
Tanque & 4,30 & 574,98 & Potável & Não \\
Máquina de lavar louça & 3,36 & 449,53 & Potável & Não \\
Pia da cozinha & 2,92 & 390,94 & Potável & Não \\
Lavatório & 2,55 & 340,60 & Potável & Sim \\
Lavagem de piso & 1,62 & 216,05 & Pluvial & Não \\
Filtro de água & 0,04 & 52,88 & Potável & Não \\
Outros & 0,03 & 4,36 & Pluvial & Não \\
\hline
\end{tabular}

Apesar da divergência em relação a quantidade de água consumida por pessoa, foi possível ver que a distribuição deste uso está em concordância com os dados disponíveis na literatura. A comparação pode ser vista na Tabela 2.

Tabela 2. Distribuição de consumo (Fonte: ${ }^{1}$ DECA, 2003 apud Marinoski; Ghisi; Gómez, 2004 e ²Sabesp, 2003 apud Marinoski; Ghisi; Gómez, 2004)

\begin{tabular}{cccccc}
\hline \multicolumn{2}{c}{ Residência em Içara } & DECA & & EUA $^{\mathbf{2}}$ \\
\hline Vaso sanitário & $38,20 \%$ & Vaso Sanitário & $29 \%$ & Vaso sanitário & $40 \%$ \\
Chuveiro & $29,68 \%$ & Banho & $28 \%$ & Banhos & $30 \%$ \\
Máquina de lavar roupa & $16,94 \%$ & Pia da cozinha & $17 \%$ & $\begin{array}{c}\text { Máquina lavar } \\
\text { roupa/louça }\end{array}$ & $15 \%$ \\
Tanque & $4,30 \%$ & Máquina de lavar roupas & $9 \%$ & Vazamentos & $5 \%$ \\
Máquina de lavar louça & $3,36 \%$ & Lavatório & $6 \%$ & Cozinha & $10 \%$ \\
Pia da cozinha & $2,92 \%$ & Tanque & $6 \%$ & & \\
Lavatório & $2,55 \%$ & Máquina de lavar louça & $5 \%$ &
\end{tabular}




\section{Revista Técnico-Cientifica de Engenharia Civil CIVILTEC}

reuso.

$\begin{array}{cc}\text { Lavagem de piso } & 1,62 \% \\ \text { Filtro de água } & 0,04 \% \\ \text { Outros } & 0,03 \%\end{array}$

Assim, computa-se que $57 \%$ da água potável utilizada pode ser substituída por água de

Observa-se que o volume de água cinza produzido só é suficiente para suprir $51 \%$ da demanda pela mesma, gerada pelo vaso sanitário. Então, caso opte-se pelo uso de água cinza juntamente com água pluvial, a percentagem de substituição de água potável cai para 38\%, uma vez que os sistemas de água cinza e pluvial devem ser individualizados (SHAFFER; LEGGETT, 2002; SANTOS, 2018).

A partir dos dados de precipitação, encontrou-se uma média mensal de chuva para a cidade de Içara/SC igual a 132,26 mm. Foram considerados para o cálculo, os 283,37 $\mathrm{m}^{2}$ de área de cobertura servida de calhas. Adotou-se coeficiênte de runoff igual 0,8 e o fator de captação recomendado pela NBR 15527:2019, igual a 0,85. Assim, utilizando a Eq. 1, o valor mensal de chuva aproveitável é igual a 25.484,88 L.

Avaliou-se, neste momento, que o volume de chuva precipitado é suficiente para suprir toda a demanda de água de reuso, sendo desnecessário utilizar águas cinzas.

Ao dimensionar o reservatório, para a aplicação do método de Rippl, foram usadas as médias mensais de precipitação, já para o método da Simulação e para o programa Netuno foram usados os volumes de precipitação diários.

A Tabela 3 mostra o dimensionamento através de Rippl. Observa-se que para todos os meses o volume de água no reservatório no tempo $\left(S_{t}\right)$ foi negativo, indicando que a quantidade de água de chuva mensal supera o necessário.

Tabela 3. Dimensionamento por Rippl para demanda mesnal de $13,37 \mathrm{~m}^{3}$ e Area de aptação e $238,37 \mathrm{~m}^{2}$

\begin{tabular}{ccccc}
\hline Mês & $\begin{array}{c}\text { Chuva Média Mensal } \\
(\mathrm{mm})\end{array}$ & $\begin{array}{c}\text { Volume chuva } \\
\text { aproveitável }\left(\mathrm{m}^{3}\right)\end{array}$ & $\begin{array}{c}\text { Volume no reservatório } \\
\left(\mathrm{m}^{3}\right)\end{array}$ & $\begin{array}{c}\text { Diferença } \\
\text { acumulada } \\
\left(\mathrm{m}^{3}\right)\end{array}$ \\
\hline Janeiro & 181,21 & 34,92 & $-21,55$ & 0 \\
Fevereiro & 162,31 & 31,28 & $-17,90$ & 0 \\
Mar & 144,38 & 27,82 & $-14,45$ & 0 \\
Abr & 105,40 & 20,31 & $-6,94$ & 0 \\
Mai & 123,74 & 23,84 & $-10,47$ & 0 \\
Jun & 98,61 & 19,00 & $-5,63$ & 0 \\
Jul & 118,13 & 22,76 & $-9,39$ & 0 \\
Agosto & 116,54 & 22,46 & $-9,08$ & 0 \\
Setembro & 138,15 & 26,62 & $-13,25$ & 0
\end{tabular}




\section{Revisto Térico-Cientifica \\ de Engenharia Civil CIVILTEC}

\begin{tabular}{ccccc} 
Outubro & 139,60 & 26,90 & $-13,53$ & 0 \\
Novembro & 129,56 & 24,97 & $-11,59$ & 0 \\
Dezembro & 126,46 & 24,95 & $-11,57$ & 0 \\
\hline
\end{tabular}

Como o método de Rippl trabalha com volumes mensais de precipitação e de consumo, quando há um volume de chuva maior que a demanda necessária para o mês, o método entende que não há necessidade de armazenamento, pois sempre haverá água disponível, assim, qualquer volume de reservatório seria suficiente para o sistema. Desta forma, não foi possível fixar um volume de reservatório. Entretando, ressaltamos que as precipitações não ocorrem de forma igualmente distribuídas durante os dias do mês, o que acarretaria provável necessidade de suprir a demanda de água não potável com água da rede.

$\mathrm{Na}$ determinação do volume de reservatório pelo método da Simulação, foram estipulados e fixados volumes de reservatórios e verificado qual percentual de demanda o mesmo atendia. Adotou-se um volume de descarte de escoamento inicial igual a $1 \mathrm{~mm}$, valor corroborado por Fontanela e Back (2010), Schroeder (2016) e Mandelli e Cauduro (2018). Essa relação pode ser vista na Figura 3.

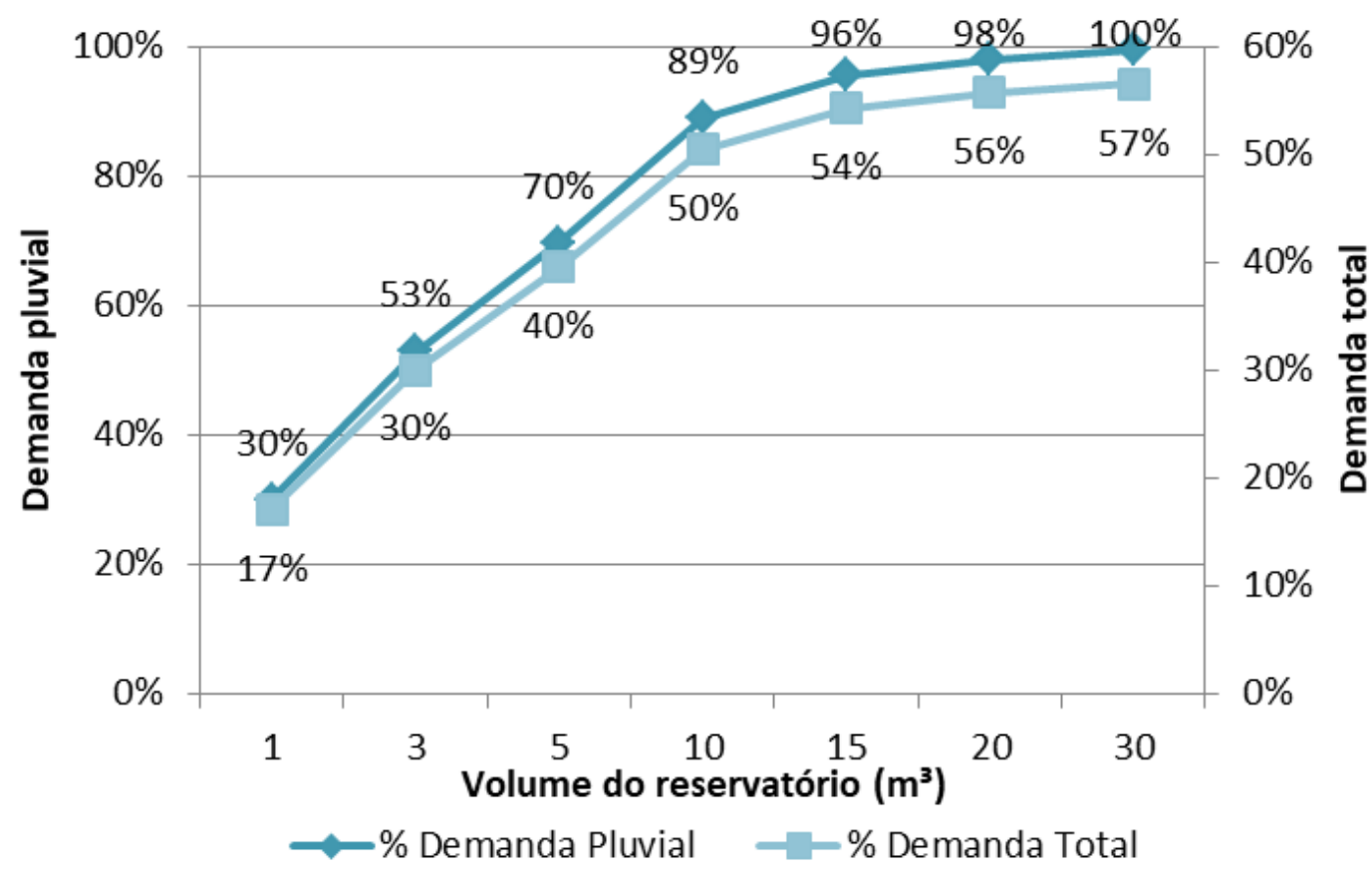

Figura 3. Dimensionamento por Simulação 


\section{Revista Técnico-Cientifica \\ de Engenharia Civil CIVILTEC}

Vê-se que o volume de reservatório igual a 30.000 litros atende a 100\% da demanda de água pluvial, correspondente a 57\% da demanda total da edificação. Observa-se, também, que volumes menores de reservatório, 5.000 L e 10.000 L, já representam uma economia de $40 \%$ e $50 \%$, respectivamente.

Além dos dados já citados, no programa Netuno informou-se o volume de descarte de escoamento inicial igual a $1 \mathrm{~mm}$. Na Figura 4 observa-se o gráfico gerado pelo programa.

De acordo com o Netuno, o valor ideal de reservatório é de 6.000 litros, pois atinge o potencial de economia de água potável igual a 57\%, ou seja, 100\% da demanda pluvial. O volume comercial mais próximo é de 5.000 litros e representa 56\% de economia.

A diferença de resultados apresentada pelos métodos já era esperada, pois foi também foi encontrada por Rupp, Munarim e Ghisi (2011, p.54) e Fontanela e Back (2010) em seus trabalhos.

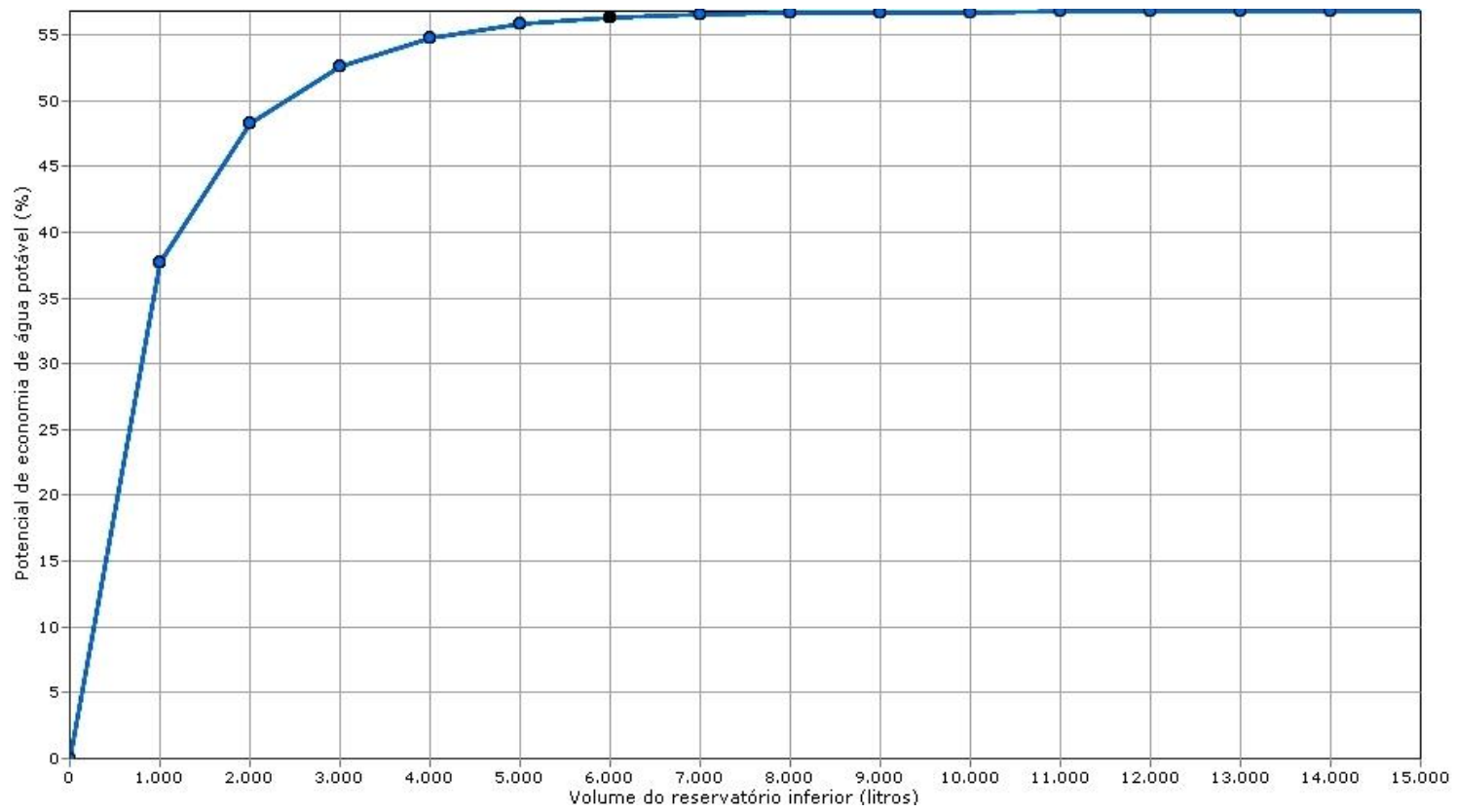

Figura 4. Dimensionamento pelo programa Netuno

Ressalta-se que os equipamentos nos quais haverá uso de água pluvial são pontos consumo para fins não potáveis e, embora não seja necessário um alto grau de purificação, deve haver filtragem (MARINOSKI; GHISI; GÓMEZ, 2004). A mesma será feita através de filtro autolimpante. 


\section{Revista Técnico-Cientifica de Engenharia Civil CIVILTEC}

Através da análise dos resultados dos dimensionamentos de reservatório, optou-se por utilizar uma cisterna de 5.000 litros. A escolha foi feita ponderando também o tamanho comercial da mesma e o espaço no terreno para instalação. A Figura 5 mostra uma representação da instalação da cisterna.

Com essa seleção, pode-se economizar mensalmente nesta residência 40\%, segundo o método da Simulação e 56\%, segundo o programa Netuno, de água da concessionária, o que representa, em média, um volume entre 5.348 e 7.488 litros de água potável.

Na etapa de caracterização de consumo e oferta de águas, verificou-se que, ao optar por usar água cinza na edificação, o potencial de economia de água potável diminui e, na etapa de avaliação de regimes de chuvas, verificou-se que o volume precipitado é suficiente para suprir toda a necessidade de água de reuso da edificação. Assim, fez-se a escolha de não utilizar água cinza nesta residência. Contudo, para fins acadêmicos, o volume de reservatório de água cinza foi calculado. Considerou-se a demanda de água cinza gerada pelo vaso sanitário, já referido na Tabela 1. O valor demandado é igual a $0,17026 \mathrm{~m}^{3} \mathrm{~d}^{-1}$. Assim, o volume do reservatório necessário é de 170 litros, ou 200 litros se respeitado o volume comercial.

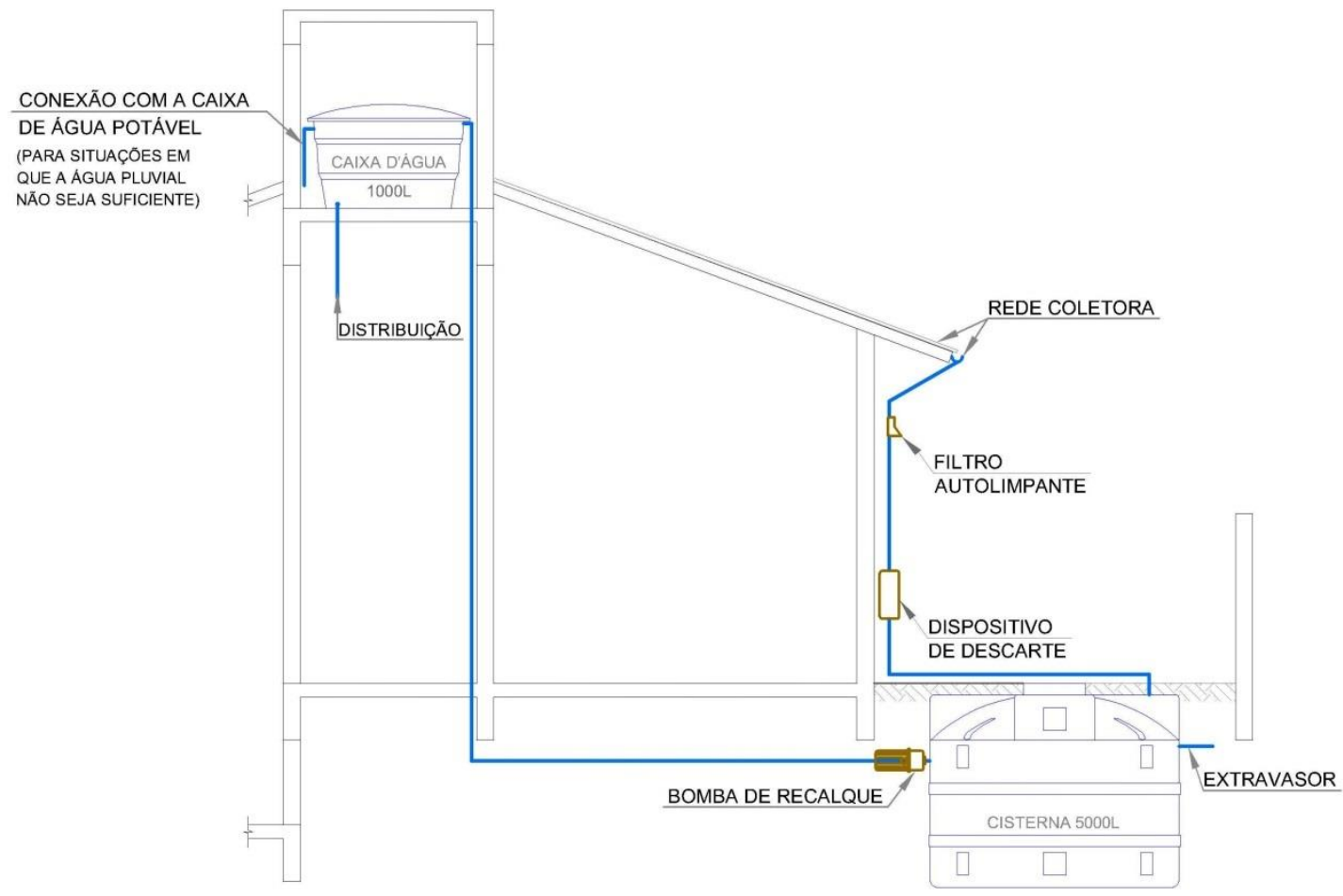




\section{Revista Técnico-Cientifica \\ de Engenharia Civil CIVILTEC}

Figura 5. Corte esquemático

\section{Conclusão}

Este trabalho propôs calcular o potencial latente de redução do consumo de água potável de uma edificação unifamiliar localizada no município de Içara/SC através do estudo de demanda de água, caracterização de consumo, análise da capacidade de coleta de água pluvial e de produção de água cinza e dimensionamento de reservatório.

A residência estudada possui cinco moradores que consomem um valor diário per capita de água $21 \%$ inferior à média da cidade. Verificou-se que devido a produção de águas cinzas não ser suficiente para suprir o abastecimento dos vasos sanitários, optar por usá-la na edificação acarretaria um menor potencial de economia de água. Estes fatos salientam a importância de estudar cada edificação individualmente, pois suas características como construção e os hábitos de seus usuários influenciam de forma relevante nos resultados. Neste caso, de forma contraintuitiva, a implementação de duas estratégias de reuso de água geraria maior consumo de água potável.

A atualização de 2019 da NBR 15527 não mais determina formas de dimensionamento para reservatórios, somente informa quais critérios devem ser considerados pelo projetista. Usando dois métodos citados na versão anterior da norma e um programa computacional, chegou-se a resultados diversos. Como o volume de precipitação captado pela cobertura superou a demanda de água pluvial, o Método de Rippl não gerou valor de reservatório. Em contra partida, o método de Simulação e o programa Netuno determinaram valores diferentes para alcançar a substituição máxima. Dito isto, a escolha do volume da cisterna, 5.000L, foi feita ponderando os dois cálculos, os tamanhos comercializados e a área de terreno disponível para instalação. A economia de água potável alcançada ficou entre 5.348 L e 7.488 L por mês, o que representa entre $40 \%$ e $56 \%$ do total consumido.

Sabendo que além do valor monetário economizado com a redução de consumo deve ser considerado o custo da instalação, ainda mais em uma residência já construída onde os 


\section{Revista Técnico-Cientifica de Engenharia Civil CIVILTEC}

incômodos de obra podem afetar os usuários, sugere-se que em um trabalho futuro calcule-se a viabilidade da implementação deste sistema.

\section{Citações e referências}

ANA; FIESP; SINDUSCON-SP. Conservação e reúso da água em edificações. São Paulo: Prol Editora Gráfica, 2005.

ASSOCIAÇÃO BRASILEIRA DE NORMAS TÉCNICAS. NBR 15527: Água da Chuva Aproveitamento de água de chuva de coberturas em áreas urbanas para fins não potáveis Requisitos. Rio de Janeiro, 2007.

ASSOCIAÇÃO BRASILEIRA DE NORMAS TÉCNICAS. NBR 15527: Aproveitamento de água de chuva de coberturas em áreas urbanas para fins não potáveis - Requisitos. Rio de Janeiro, 2019.

BRAGA, E. D. Estudos de reuso de água em condomínios residenciais. 2009. $144 \mathrm{f}$. Dissertação (Mestrado) - Programa de Pós-Graduação em Engenharia de Energia, Mestrado em Ciências em Engenharia de Energia, Universidade Federal de Itajubá, Itajubá, 2009.

BRASIL. Lei $\mathbf{n}^{\circ}$ 9.433, de 08 de janeiro de 1997. Institui a Política Nacional de Recursos Hídricos, cria o Sistema Nacional de Gerenciamento de Recursos Hídricos, regulamenta o inciso XIX do art. 21 da Constituição Federal, e altera o art. $1^{\circ}$ da Lei $n^{\circ} 8.001$, de 13 de março de 1990, que modificou a Lei n ${ }^{\circ}$ 7.990, de 28 de dezembro de 1989. Brasília, DF: Presidência da República, 1997. Disponível em: http://www.planalto.gov.br/ccivil_03/LEIS/L9433.htm. Acesso em: 13 abr. 2020.

BOLSONARO, J. M., MENDONÇA, A. L. D. A., GUEDES, P., DE FREITAS, T. G., SALLES, R. D. A., \& MARINHO, R. (2020). Lei no 14.026, de 15 de julho de 2020.

BRASIL. Ministério do Desenvolvimento Regional. Secretaria Nacional de Saneamento - SNS. Diagnóstico de Água e Esgoto. Mapa de Indicadores de Água. 2018. Disponível em: http://appsnis.mdr.gov.br/indicadores/web/agua_esgoto/mapa-agua. Acesso em: 25 nov. 2020.

CERQUEIRA, G. A.; PINTO, H. S.; FARIA, I. D.; BAPTISTA, J. C. R.; KASSMAYER, K.; SOUZA, L.B.G. de; KÖHLER, M.A.; ABBUD, O.A.; PINTO, C. V. A Crise Hídrica e suas Consequências. Núcleo de Estudos e Pesquisas/CONLEG/Senado, abril/2015 (Boletim do Legislativo $n^{\circ} 27$, de 2015). Brasília, 2015. Disponível em: www.senado.leg.br/estudos. Acesso em 13 abr. 2020.

DANTAS, C. V . C. Uso racional da água em uma edificação na zona rural de Pernambuco. 2017. 21F. Artigo Científico (Graduação) - Universidade Federal do Rio Grande do Norte, Centro de Tecnologia, Departamento de Engenharia Civil. Natal, RN, 2017. 
FENDRICH, R. Coleta, armazenamento, utilização e infiltração das águas pluviais na drenagem urbana. 2002. 547 f. Tese (Doutorado) - Curso de Pós-Graduação em Geologia Ambiental, Geologia, Universidade Federal do Paraná, Curitiba, 2002.

FONTANELA, L.; BACK, A. J. Avaliação de metodologias para dimensionamento de reservatórios para aproveitamento de água pluvial. 2010. 68 f. TCC (Graduação) - Curso de Engenharia Civil, Engenharia Civil, Universidade do Extremo Sul Catarinense, Criciúma, 2010.

GONÇALVES, R. F. (Coord.). Uso racional da água e energia. 1. ed. Rio de Janeiro: Prosab/ABES, 2009. 352 p.

GHISI, E.; CORDOVA, M. M. Netuno 4. Programa computacional. Universidade Federal de Santa Catarina, Departamento de Engenharia Civil. Disponível em: http://www.labeee.ufsc.br/. 2014. Acesso em: 15 out. 2020

JEFFERSON, B.; LAINE, A.; PARSONS, S.; STEPHENSON, T.; JUDD, S. Technologies for domestic wastewater recycling. Urban Water. 1, p. 285-292, 1999.Cranfield, 1999.

MACCARINI, M. G. C.; CAUDURO, F. Estudo da viabilidade de implantação de sistema de reuso de águas cinzas para fins não potáveis em um edifício multifamiliar: estudo de caso. 2017. 24 f. TCC (Graduação) - Curso de Engenharia Civil, Engenharia Civil, Universidade do Extremo Sul Catarinense, Criciúma, 2017. Disponível em: http://repositorio.unesc.net/handle/1/5568. Acesso em: 28 out. 2020.

MANDELLI, T. J.; CAUDURO, F. Estudo de viabilidade de implantação do aproveitamento das águas pluviais em uma edificação universitária. 2018. $11 \mathrm{f}$. TCC (Graduação) - Curso de Engenharia Civil, Engenharia Civil, Universidade do Extremo Sul Catarinense, Criciúma, 2018. Disponível em: http://repositorio.unesc.net/handle/1/6313. Acesso em: 08 out. 2020

MARINOSKI, D. L.; GHISI, E.; GÓMEZ, L.A. Aproveitamento de água pluvial e dimensionamento de reservatório para fins não potáveis: estudo de caso em um conjunto residencial localizado em Florianópolis-SC. In: I CONFERÊNCIA LATINO-AMERICANA DE CONSTRUÇÃO SUSTENTÁVEL E X ENCONTRO NACIONAL DE TECNOLOGIA DO AMBIENTE CONSTRUÍDO, 18-21, 2004, São Paulo. Anais... São Paulo: claCS e ENTAC, 2004

MAY, S. Caracterização, tratamento e reúso de águas cinzas e aproveitamento de águas pluviais em edificações. 2009. 223f. Tese (doutorado) - Escola politécnica da universidade de São Paulo. Departamento de Engenharia Hidráulica e Sanitária. São Paulo, 2009.

NGIGI, S. N. Optimization of Rainwater Catchment Systems Design Parameters in the Arid and Semiarid Lands of Kenya. Proceedings of KSAE, Nairobi, Kenya. 1999.

RUPP, R. F.; MUNARIM, U.; GHISI, E. Comparação de métodos para dimensionamento de reservatórios de água pluvial. Ambiente Construído, [S.L.], v. 11, n. 4, p. 47-64, dez. 2011. 


\section{Revisto Téenico-Cientifica de Engenharia Civil CIVILTEC}

FapUNIFESP (SciELO). http://dx.doi.org/10.1590/s1678-86212011000400005. Disponível em: $\quad$ http://www.scielo.br/scielo.php?script=sci_arttext\&pid=S1678$86212011000400005 \& \operatorname{lng}=$ pt\&nrm=iso. Acesso em: 14 out. 2020

SANTA CATARINA. Lei $\mathbf{n}^{\circ} \mathbf{1 5 . 2 4 9}$, de 03 de agosto de 2010. Altera dispositivos da Lei $\mathbf{n}^{\circ}$ 9.022, de 1993, que dispõe sobre a instituição, estruturação e organização do Sistema Estadual de Gerenciamento de Recursos Hídricos. Florianópolis: Governador do Estado de Santa Catarina, 2010. Disponível em: http://leis.alesc.sc.gov.br/html/2010/15249_2010_lei.html. Acesso em: 13 abr. 2020.

SANTANA, D.; AMORIM, C. N. D. Reúso de água em edificações: premisas e perspectivas para o contexto brasileiro. Sistemas Prediais, São Paulo, v.2, n.1, Setembro, p.32-37. 2007.

SANTOS, S. A. Análise comparativa do uso de sistemas de aproveitamento de águas pluviais e reúso de águas cinzas na Rodoviária do Plano Piloto, Brasília-DF. 2018. 144f. Dissertação (Mestrado) - Programa de Pós-Graduação em Arquitetura e Urbanismo, Faculdade de Arquitetura e Urbanismo, Universidade de Brasília, Brasília, DF, 2018.

SCHROEDER, A. K. Estudo Comparativo de Viabilidade Econômica do Aproveitamento de Água Pluvial e Reuso de Água Cinza em uma residência. 2016. 129 f. TCC (Graduação) - Curso de Engenharia Sanitária e Ambiental, Centro Tecnológico, Universidade Federal de Santa Catarina, Florianópolis, 2016.

SHAFFER, P.; LEGGETT, D. Buildings that save water-rainwater and greywater use. Proceedings of The Institution of Civil Engineers-municipal Engineer - PROC INST CIVIL ENG MUNIC ENG. 151.. p.189-196, 2002. 